\title{
Pharmacoeconomics of Selected Essential Medicines for Common Ailments in Sonipat District, Haryana, I ndia
}

\author{
Anjali Goyal, Neeraj Gilhotra \\ Department of Pharmaceutical Sciences, Maharshi Dayanand University, Rohtak - 124 001, Haryana, India.
}

\author{
ARTICLE INFO \\ Article history: \\ Received on: 12/02/2015 \\ Revised on: 06/03/2015 \\ Accepted on: 17/04/2015 \\ Available online: 27/06/2015 \\ Key words: \\ Essential medicines, \\ Accessibility, Affordability, \\ Out-of-pocket expenditure, \\ Price to patient.
}

\begin{abstract}
Inappropriate access of essential medicines contributes substantially to out-of-budget expense. Out-of-pocket expenditure makes a vital (up to 70\%) health expenditure in India. This research study was conducted to investigate the comparative relative price to patient of selected essential medicines used for common ailments in Sonipat city. A research study on a price-to-be-paid to patient of selected essential medicines for selected common ailments was conducted. Standardized methodology of World Health Organization and Health Action International was employed. Prices were compared to an International Reference Price (Median Price Ratio). The study was conducted on all the two hundred retail pharmacy outlets attached to all residential areas of Sonipat city. The difference between lowest price and highest price (of available medicine) ranged from $0.30-40 \%$ in case of antimicrobials and $0.17-3.4 \%$ in case of antiulcers, antiemetics and analgesics. Dissemination of well documented information on affordability to medicine consumers may enhance consumer demand for lower price medicine and thus may serve to enhance the availability of demanded medicine in all the areas of Sonipat city.
\end{abstract}

\section{INTRODUCTION}

The district Sonipat comes into existence on December 22, 1972. According to Census 2011, total population of the Sonipat city (with in Municipal Council) includes 277053 people. The concept of essential medicines was launched in 1977, with the publication of the first World Health Organization's Model List of Essential Medicines. In 2007, World Health Organization (WHO) survey of 156 countries showed that $86 \%$ of responding countries have a National Essential Medicine List (EML), including all low-income countries and most middle-income countries (WHO, 2007). The present study is perhaps the only study that compares the relative price to patients for selected essential medicines used in the treatment of some common ailments in a single district of any state. This research study covers whole of Sonipat and serve to document the relative price to patients for selected essential medicines used in the treatment of some selected common ailments in different geographical areas of Sonipat city. The method used in the present study is based on World Health Organization (WHO), Geneva Switzerland and Health Action International Global (HAI),

\footnotetext{
* Corresponding Author

Neeraj Gilhotra, Department of Pharmaceutical Sciences, Maharshi Dayanand University, Rohtak - 124 001, Haryana, India.

Email: neerajmdu@rediffmail.com
}

Amsterdam Netherland Guidelines (WHO, 2003 \& 2008). World Health Organization (WHO) celebrated the $30^{\text {th }}$ of the Model List of Essential Medicines in 2007. World Health Organization (WHO) promotes Essential Medicine List (EML) to facilitate equality in access to medicines over the globe (WHO, 2011). Essential medicine list has been formulated to satisfy the priority health care needs of community in terms of availability and affordability of essential medicines (WHO, 2012). According to the Universal Declaration of Human Rights and the Millennium Development Goals (UN, 2008 \& 2012), the World Health Organization (WHO) recommends the global implementation and regular updates of the national essential medicines list for ensuring availability of essential medicines in middle and low income countries (WHO, 2012). Since 1977, World Health Organization (WHO) published the first model list of essential medicines which is revised every two years by the WHO Expert Committee on the selection and use of essential medicines (WHO, 1977). This model list of World Health Organization (WHO) serves as a guide for the development of National essential medicines list (NEML) (Van den et al., 2011). This concept of essential medicines has become global and more than 150 countries have their national list of essential medicines and over 100 countries have a national medicines policy (Hogerzeil, 2004 \& 2006). Among these, 94\% use the essential medicines list (EML) as a basis for public procurement of price to access essential medicines 
majority for the poor (Van den et al., 2011). Recently, the Ministry of Health and Family Welfare (MOH and FW) Government of India (GOI) (WHO, 2004 \& 2005) revised the National list of essential medicines India in June 2011 (NEML, 2003 \& 2011). The major challenge for National health care system is to provide appropriate health products in a reasonable, reliable and efficient way, accessible to majority of the community (WHO, 2010). Essential medicines list (EML) of the World Health Organization (WHO) provides a blueprint for selecting cost effective and high quality medicines for nations (Wertheimer and Santella, 2007). Since 2002, Essential medicines satisfy the priority health care needs of the community; selected with regard to public health relevance, evidence on efficacy, safety and at a comparative cost intended to be available at all times in adequate amounts and in the appropriate dosage forms at a price that individual and community can easily afford (WHO, 2003 \& 2014). Out-of-pocket expenditure includes cost-sharing, self medication and other expenditure paid directly by private households (OECD, 2011). Up to $20-60 \%$ of medicines accounts for health spending in low and middle income countries (LMIC), compared with 18\% in countries of the organization for Economic Co-operation and Development (OECD) (WHO, 2013). In developing countries a significant population (up to $90 \%$ ) purchase medicines through out-of-pocket payments, making medicines the largest family expenditure item after food (WHO, 2013). Out-of-pocket expenditures accounted for almost half (41-56\%) of the total health expenditure on medicines in low and middle income countries (LMIC) (Wagner et al., 2010).

\section{MATERIAL AND METHODS}

\section{Background}

Sonipat, the district of Haryana is located in the southeast of the State of Haryana. At the district level, Health services of the Government is rendered through 100 bedded hospital at Sonipat town, 7 community health centers (CHC) including one at Gohana town with 50 beds, and 29 primary health Centre(PHC). Sonipat city has Hospital formulary of Essential Medicines List. To check out the relative price to patients for selected essential medicines used in the treatment of some selected common ailments, all the retail pharmacy outlets of Sonipat city were included in this study.

\section{Sampling}

This baseline data collection research study was conducted at retail pharmacy outlets in different geographical areas of Sonipat city.

\section{Medicines Surveyed}

Eighteen essential medicines for common ailments were selected. Of these 18 essential medicines, two for Palliative care i.e. Ibuprofen, Paracetamol, four for gastrointestinal disturbances i.e. Omeperazole, Ranitidine, Ondansetron, Metoclopromide, ten antibacterials i.e. Metronidazole, Amoxicillin, Ciprofloxacin,
Azithromycin, Erythromycin, Cefixime, Cephalexin, Ofloxacin, Ampicillin, Gentamycin and two antifungals i.e. Miconazole, Clindamycin in different dosage forms (Table 1) were selected. The basis for their selection was that these eighteen essential medicines have been included in the WHO Essential Medicine List, National List of Essential Medicine India and Hospital Formulary of Sonipat city.

Table 1: List of Selected Essential Medicines for Selected Common Ailments.

\begin{tabular}{lll}
\hline S. no. & Essential Medicine & Dossage form \\
\hline 1 & Ibuprofen & Tab \\
2 & Paracetamol & Tab \\
3 & Omeperazole & Tab/cap \\
4 & Ranitidine & Tab \\
5 & Ondansetron & Tab \\
6 & Metaclopromide & Tab \\
7 & Metronidazole & Tab \\
8 & Amoxicillin & Tab/cap \\
9 & Ciprofloxacin & Tab/cap \\
10 & Azithromycin & Tab/cap \\
11 & Erythromycin & Tab/cap \\
12 & Cefixime & T b/c p \\
13 & Cephalexin & T b/c p \\
14 & Ofloxacin & Tab \\
15 & Ampicillin & Tab/cap \\
16 & Gentamycin & Tab/in \\
17 & Miconazole & Tab/ointment \\
18 & Clindamycin & Cap/ointment \\
\hline
\end{tabular}

As per WHO/HAI methodology, data was collected for both the originator brand and the lowest- priced generic found at each retail pharmacy outlet. In India, originator brands have not any additional recognition as originator brand. The same molecules other than originator brands manufactured by other companies with different trade names are branded generics.

\section{Data Collection}

For collecting data, different geographical areas as shown in Figure 1 were decided to cover. A standardized format for data collection was prepared using standardized WHO \& HAI (World Health Organization \& Health Action International) manual. A well documented baseline data was collected on relative price to be paid by reference of medicine consumers; develop an effective framework for medical health and improve equitable access to essential medicines for common ailments in Sonipat city. This baseline data was collected at retail Pharmacy outlets of different geographical areas in Sonipat city.

\section{Methodology}

\section{Step 1: Price variation between selected essential medicines in} different geographical areas of Sonipat city

In this procedure, data was collected on unit price of essential medicines for common ailments given by retail pharmacist. Mean availability of mean price of specific essential medicine was calculated at specific area. Mean price for all essential medicines were calculated in different geographical areas. After the mean price, highest and lowest mean price of all essential medicines for common ailments were calculated in Sonipat city. 


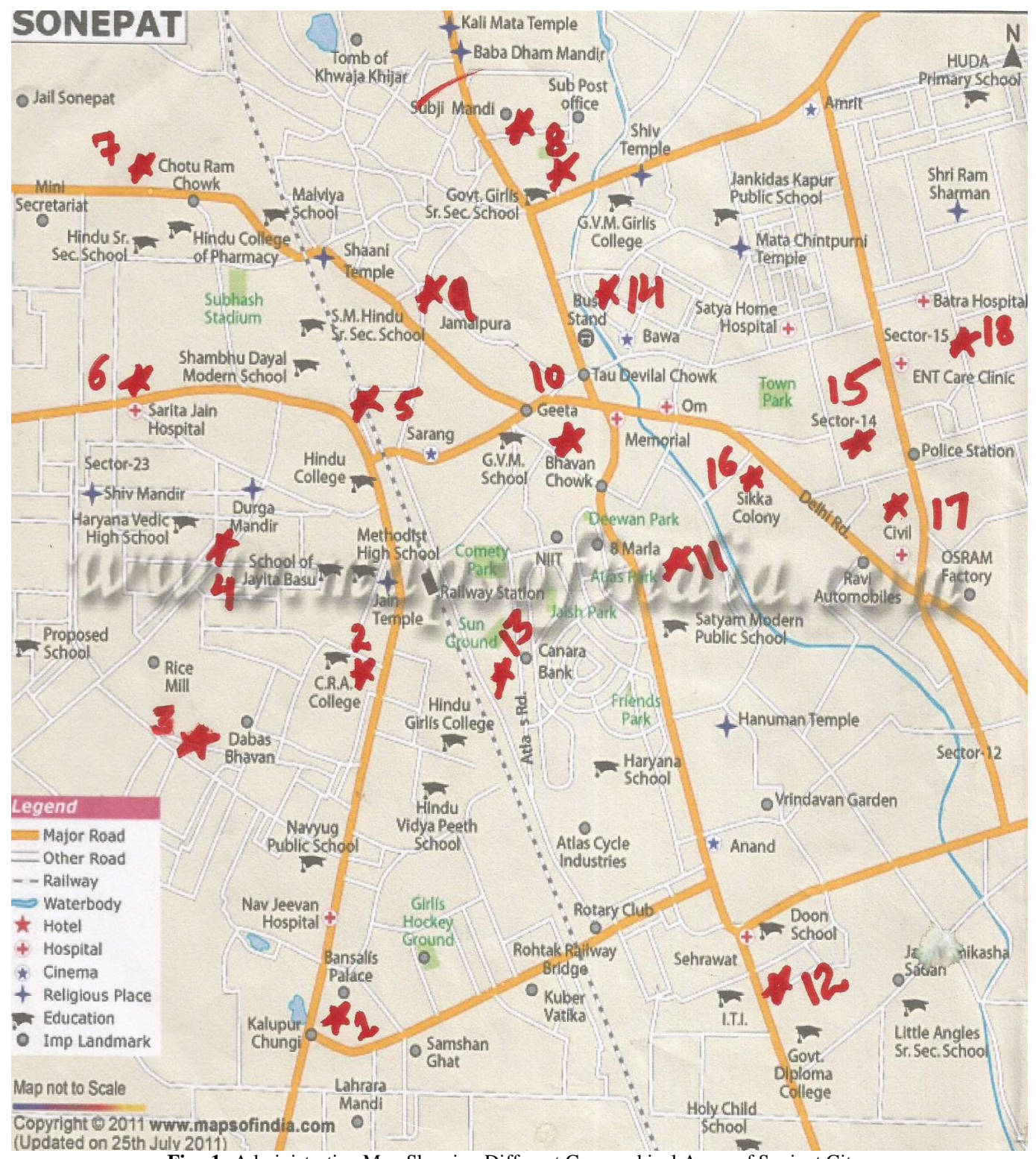

Fig. 1: Administrative Map Showing Different Geographical Areas of Sonipat City.

Step 2: Median unit price ratio and median INT. Supplier unit prices of selected essential medicines

The median price ratio (MPR) is the local median unit price of a medicine in comparison with the median unit price found in the Management Sciences for Health (MSH) Price Indicator Guide, 2013. In this procedure data was collected on the format i.e. unit price of essential medicines for common ailments given by retail pharmacist. Median unit price of all selected essential medicine was calculated by dividing total price with average unit price in different geographical areas. As median unit price of selected essential medicine for common ailments was calculated as above and median INT. (International) supplier unit prices was described in Management of Sciences Health (MSH) Price Indicator Guide, 2013, then comparison between median unit price in INR (Indian rupees) and median INT. Supplier unit price in MSH was performed.

\section{Data processing}

Availability of price variation in mean prices of selected essential medicines for common ailments given by retail pharmacist to consumers was analyzed by standard mean error.

\section{Ethical approval}

Ethical approval of the study was obtained from Municipal Council of Sonipat city.

\section{RESULTS}

Median INT. Supplier unit prices, Median unit price in INR and Percent Availability of Selected Essential Medicines

Median INT. (International) supplier prices were found in MSH (Management Sciences for Health) Price Indicator Guide, 
2013 (WHO, 2013) and Median unit prices were calculated from minimum and maximum unit prices of selected essential medicines at pharmacy outlets in Indian rupees (INR). Huge price differences had been observed in between median INT. (International) supplier prices were found in MSH (Management Sciences for Health) Price Indicator Guide, 2013 and Median unit prices in INR (Indian rupees). Median INT. Supplier unit prices and median unit price in INR for selected essential medicines for selected common ailments at retail pharmacy outlets of Sonipat city was shown in table 2

Table 2: Median INT. Supplier Unit Price in MSH and Median unit price in INR, of Selected Essential Medicines for Selected Common Ailments in Sonipat City.

\begin{tabular}{lcc}
\hline \multicolumn{1}{c}{$\begin{array}{c}\text { Essential } \\
\text { Medicines }\end{array}$} & $\begin{array}{c}\text { Median INT. Supplier } \\
\text { Unit Price in MSH }\end{array}$ & $\begin{array}{c}\text { Median Unit } \\
\text { price in INR }\end{array}$ \\
\hline Ibuprofen & 0.0113 & 0.755 \\
Paracetamol & 0.0048 & 0.895 \\
Omeperazole & 0.0213 & 2.775 \\
Ranitidine & 0.026 & 0.6 \\
Ondansetron & 0.62 & 4.1 \\
Metaclopromide & 0.0055 & 1.95 \\
Metronidazole & 0.0101 & 0.71 \\
Amoxicillin & 0.0173 & 3.935 \\
Ciprofloxacin & 0.0418 & 6.475 \\
Azithromycin & 0.3542 & 18.65 \\
Erythromycin & 0.0393 & 5.775 \\
Cefixime & 0.2028 & 13.43 \\
Cephalexin & 0.0443 & 10.92 \\
Ofloxacin & 0.048 & 4.83 \\
Ampicillin & 0.018 & 3.725 \\
Gentamycin & 0.1098 & 9.95 \\
Miconazole & 0.0161 & 52.75 \\
Clindamycin & 0.1084 & 75 \\
\hline INT: International, MSH: Management Sciences for & Health, INR: Indian \\
Rupees, S.E.M.: Standard Error Mean & \\
& &
\end{tabular}

Table 3: Price Variation between Highest \& Lowest Mean Price Range of Selected Essential Medicines in Sonipat City. Values are Expressed as Standard Error Mean.

\begin{tabular}{lcc}
\hline \multicolumn{1}{c}{$\begin{array}{c}\text { Essential } \\
\text { Medicines }\end{array}$} & $\begin{array}{c}\text { Lowest Mean Price Range } \\
\mathbf{\pm S . E . M . ~}\end{array}$ & $\begin{array}{c}\text { Highest Mean } \\
\text { Price } \\
\text { Range } \pm \text { S.E.M }\end{array}$ \\
\hline Ibuprofen & $0.67 \pm 0.92$ & $0.84 \pm 1.17$ \\
Paracetamol & $0.72 \pm 0.92$ & $1.07 \pm 1.17$ \\
Omeperazole & $1.99 \pm 0.92$ & $3.56 \pm 1.17$ \\
Ranitidine & $0.5 \pm 0.92$ & $0.7 \pm 1.17$ \\
Ondansetron & $2.4 \pm 0.92$ & $5.8 \pm 1.17$ \\
Metaclopromide & $0.85 \pm 0.92$ & $3.05 \pm 1.17$ \\
Metronidazole & $0.56 \pm 0.92$ & $0.86 \pm 1.17$ \\
Amoxicillin & $2.34 \pm 0.92$ & $5.53 \pm 1.17$ \\
Ciprofloxacin & $5.12 \pm 0.92$ & $7.83 \pm 1.17$ \\
Azithromycin & $16.33 \pm 0.92$ & $20.97 \pm 1.17$ \\
Erythromycin & $3.5 \pm 0.92$ & $8.05 \pm 1.17$ \\
Cefixime & $8.11 \pm 0.92$ & $18.75 \pm 1.17$ \\
Cephalexin & $9.4 \pm 0.92$ & $12.44 \pm 1.17$ \\
Ofloxacin & $3.86 \pm 0.92$ & $5.8 \pm 1.17$ \\
Ampicillin & $2.7 \pm 0.92$ & $4.75 \pm 1.17$ \\
Gentamycin & $4.7 \pm 0.92$ & $15.2 \pm 1.17$ \\
Miconazole & $33 \pm 0.92$ & $72.5 \pm 1.17$ \\
Clindamycin & $61.67 \pm 0.92$ & $88.33 \pm 1.17$ \\
\hline
\end{tabular}

Variation in highest and lowest prices of selected essential medicines

Variation in prices for highest and lowest priced essential medicines for selected common ailments was shown in table 3 .
The price difference between lowest and highest priced essential medicines was found to be $0.30-40 \%$ in case of antibacterials and $0.17-3.4 \%$ in case of analgesics, antiulcers and antiemetics. Largest variation in prices was found in antibacterialsGentamycin $(10.5 \%)$, Cefixime $(10.64 \%)$, Clindamycin $(26.66 \%)$ and miconazole $(39.5 \%)$.

\section{DISCUSSION}

Sonipat spans a relatively small geographical area as compared to other Haryana state districts. This study would be useful to government health policy makers in providing a broad picture of the present situation regarding relative price to patients for selected essential medicines used in the treatment of some common ailments. Dissemination of well documented information on relative price to medicine consumers in all residential areas may enhance consumer demand for lower price medicine. The present study is perhaps the only study that compares the relative price to patients for selected essential medicines for common ailments in a single district of any state. This study covers whole of retail pharmacy outlets of Sonipat city and serve to document the overall relative price paid by consumers for essential medicines for common ailments in different geographical areas and shall be source of information i.e. which medicine is available in cheapest price in which area of Sonipat city. From this study, People of Sonipat will come to know about the relative price to patients for each selected essential medicine for selected common ailments in their area which is usually not known and people pay what they are asked by chemists. This information is definitely important in those cases, where medicine are to be taken for longer periods of time and out-of-pocket expenditure is high and moreover, price money goes directly from the pocket of medicine consumer. This data will be also compiled in form of booklet which shall be released for benefit of people of Sonipat city and shall serve as reference for consumers, policy makers or nongovernmental organizations interested to take up such projects.

\section{Overall relative price}

Huge price differences were observed in case of antibacterial $(0.30-40 \%)$ i.e. for certain medicines like Azithromycin, Erythromycin, Cefixime, Cephalexin, Gentamycin, Clindamycin and Miconazole. In India, for most of the medicines government does not fix the prices so only a few essential medicines are under price control. Government must intervene and regulate the prices of essential medicines that are expensive.

\section{Policy options to improve relative price}

For improving relative price to patients for essential medicines various recommendations are given such as Government to increase the budget of medicines, prepare Standard treatment guidelines (STGs) and Essential Medicine List (EML) on the basis of essential medicine concept; separate EML for primary care and hospitals; procurement and distribution of medicines on the basis of EML; prescription according to STGs 
and EML and regular monitoring and evaluating system (Quick, 2003 and Holloway, 2001). In Lebanon government implemented regressive margins for importers, wholesalers and retailers; improved transparency by publishing patient prices on the internet and in the Lebanon National Drug Index (Ewen M, 2003). In India we need to have policy actions based on documented medicine price surveys to improve access to essential medicines. Awareness programmes targeting to doctors, patients, consumers and the media should be needed that focus on the disparity in the relative price to patient for different brands of the same medicine.

\section{CONCLUSION}

The price difference between lowest and highest unit price of selected essential medicines ranged from $0.30-40 \%$ in case of antibacterials and $0.17-3.4 \%$ in case of analgesics, antiulcers and antiemetics. Most of the antibacterials except Erythromycin, Cefixime, Ofloxacin and ampicillin were found at lower prices in Old D.C. road areas of Sonipat city. Erythromycin, Cefixime, Ofloxacin and ampicillin antibacterials at higher prices were found in Suri petrol pump road, Geeta bhawan chowk, Sikka colony and Murthal road respectively. Largest variation in prices had been observed in case of antibacterials Gentamycin (10.5\%), Cefixime (10.64\%), Clindamycin (26.66\%) and Miconazole (39.5\%). Huge price differences had been observed in between median INT. (International) supplier prices found in $\mathrm{MSH}$ (Management Sciences for Health) Price Indicator Guide, 2013 and Median unit prices in INR (Indian rupees). From observation in the present study, a large variation in relative price to patient for selected essential medicines for selected common ailments had been observed in Sonipat city.

\section{REFERENCES}

Ewen M. Sound price data-sound price policies. Essential drug monitor. 2003; 33: 23.

Hogerzeil HV. The concept of essential medicines: lessons for rich countries. BMJ. 2004; 329: 1169-1172.

Hogerzeil HV, Samson M, Casanovas JV \& Rahmani-Ocora L. Is access to essential medicines as part of the fulfilment of the right to health enforceable through the courts? The Lancet 2006; 368: 305-311.

Holloway K, Combating inappropriate use of medicines. Expert Rev Clin Pharmacol. 2001; 4: 335-348.

Ministry of Health and Family Welfare, Government of India (In collaboration with WHO India Country Office): National health accounts India 2004-2005 (with provisional estimates from 2005-2006 to 2008-2009).

National list of essential medicines. 2003. Directorate General of Health Services, Ministry of Health and Family Welfare. Government of India. New Delhi, India.

National list of essential medicines of India. 2011. Directorate General of Health Services, Ministry of Health and Family Welfare. Government of India. New Delhi, India.

OECD. 2011. "Burden of out-of-pocket health expenditure", in Health at a Glance. OECD Indicators. OECD Publishing.

Quick JD. Ensuring access to essential medicines in the developing countries: a framework for action. CPT. 2003; 73: 279-283.
United Nations. 2008. The Millennium Development Goals Report (MDG Goal \#8, Target \#4) New York.

United Nations. 2011. Universal declaration of human rights: (1) everyone has the right to a standard of living adequate for the health and well-being of himself and of his family, including food, clothing, housing and medical care. Article, 25; 2012. Available at: http://www.un.org/en/documents/udhr/index.shtml\#a25.

Van den Ham R, Bero L \& Laing R. The World Medicine Situation: Selection of Essential Medicines. $3^{\text {rd }}$ Ed. World Health Organization, Geneva, Switzerland; 2011.

Wagner AK, Graves AJ, Reiss SK, Lecates R, Zhang F \& RossDegnan D. Access to care and medicines, burden of health care expenditures, and risk protection: Results from the World Health Survey. Health Policy. 2010; 100(2-3). 151-158.

Wertheimer AI \& Santella TM. Innovation and the WHO's essential medicines list: Giving credit where credit is due. Res Social Adm Pharm. 2007; 3: 137-144.

World Health Organization. 1977. The selection of essential drugs. Report of the WHO Expert Committee. WHO Technical Report Series, No. 615. Geneva, Switzerland.

World Health Organization. 2003. The selection and use of essential medicines. Report of WHO expert committee, 2002 (including the 12th Model List of Essential Medicines). WHO Technical Report, Series No. 914. Geneva. Switzerland.

World Health Organization \& Health Action International. 2003. Measuring medicine prices, availability, and affordability and price components. $1^{\text {st }}$ ed. Geneva, Switzerland.

World Health Organization. 2007. Country pharmaceutical situations. Fact book on WHO Level 1 indicators. Geneva, Switzerland.

World Health Organization \& Health Action International. 2008. Measuring medicine prices, availability, and affordability and price components. $2^{\text {nd }}$ ed. Geneva, Switzerland.

World Health Organization. 2010. Essential Medicines and Pharmaceutical Policies. Regional office for eastern Mediterranean, World Health Organization, Geneva, Switzerland. Available at: http://www.emro.who.int/emp/medicines.htm.

The WHO Essential Medicines List (EML). 2011. 30th anniversary: World Health Organization, Geneva, Switzerland.

The world medicines situation. 2011. Access to essential medicines as part of the right to health. World Health Organization. Geneva, Switzerland.

World Health Organization. 2012. Health topics/Essential medicines. Geneva, Switzerland.

World Health Organization. 2012. 20 ways the world health organization helps countries reach the millennium development goals World Health Organization, Geneva, Switzerland.

World Health Organization. 2013. "Guideline on Country Pharmaceutical Pricing Policies" World Health Organization. Geneva, Switzerland.

World Health Organization. 2013. International Drug Price Indicator Guide, MSH (Management Sciences for Health) in collaboration with the World Health Organization. Geneva, Switzerland.

World Health Organization. 2014. The selection and use of essential medicines. Report of the WHO Expert Committee, 2013 (including the 18th WHO Model List of Essential Medicines and the $4^{\text {th }}$ WHO Model List of Essential Medicines for Children). WHO Technical Report, Series 985. Geneva, Switzerland.

\section{How to cite this article:}

Anjali Goyal, Neeraj Gilhotra. Pharmacoeconomics of Selected Essential Medicines for Common Ailments in Sonipat District, Haryana, India. J App Pharm Sci, 2015; 5 (06): 083-087. 